\title{
Oracle Acquired AI Startup DataFox
}

\author{
Article history: \\ Received: 15 January 2019 \\ Sent for revision: 25 January 2019 \\ Received in revised form: 22 May 2019 \\ Accepted: 27 May 2019 \\ Available online: 4 July 2019
}

\begin{abstract}
All the major artificial intelligence based product and service providers in the software industry are acquiring the Al startup to enhance the existing features and capabilities of their offerings to customers. Oracle is no exception to this strategy. It has acquired DataFox to enhance Al powered capabilities, expand available data sources for its business intelligence software. This paper is an attempt to study various facets of DataFox acquisitions such as deal itself, DataFox capabilities (products/applications, customers, competitors), reasons for Oracle to acquire DataFox, and its impact on existing products and applications of Oracle. In addition, the paper compares the acquisition with the model suggested by Bonzom and Netessine (2016) and concludes it is more for innovation, change in culture, reaching new markets, and having Al platform and less for problem solving by analysing nine propositions.
\end{abstract}

Keywords: DataFox, Customers, Artificial Intelligence, Oracle, B2B segment, Alternatives and Competitors, Cloud Accelerator, Al Startups.

\section{Orakl preuzeo startap DataFox koji se bavi veštačkom inteligencijom}

Apstrakt: Svi glavni provajderi proizvoda i usluga zasnovanih na veštačkoj inteligenciji u softverskoj industriji preuzimaju startape za veštačku inteligenciju kako bi poboljšali postojeće karakteristike i kapacitete svoje ponude korisnicima. Orakl takođe primenjuje ovu strategiju, preuzimanjem DataFox-a kako bi poboljšao kapacitete vezane za veštačku inteligenciju, proširio dostupne izvore podataka za softver poslovne inteligencije. Ovaj rad predstavlja pokušaj proučavanja različitih aspekata preuzimanja DataFox-a,

\footnotetext{
${ }^{1}$ Management Development Institute, Gurgaon, India, knpsingh@mdi.ac.in 
Singh N.P.: Oracle Acquired Al Startup DataFox

kao što je posao sam po sebi, kapaciteti DataFox-a (proizvodi/aplikacije, korisnici, konkurenti), razlozi zbog kojih je Orakl preuzeo DataFox i kako je to uticalo na Oraklove proizvode $i$ aplikacije. Pored toga, u radu se upoređuje preuzimanje sa modelom koji su predložili Bonzom i Netessine (2016) i zaključuje da je to pre za inovacije, promene u kulturi, izlazak na nova tržišta $i$ dobijanje nove platforme za veštačku inteligenciju, a manje za rešavanje problema analizom devet predloga.

Ključne reči: DataFox, korisnici, veštačka inteligencija, Orakl, B2B segment, alternative i konkurenti, Cloud Accelerator, startapi za veštačku inteligenciju

\section{Introduction}

Large companies acquire startups to bring new technology to the market, fill technological gaps in their product portfolio, increase their existing products \& services portfolio, enhancing the capabilities of the existing portfolio of product \& services, acquire new customers for their existing products \& services, enter new market segments, buying the workforce, for increasing revenues without innovating internally, for client data, for IP, killing emerging competitions, reduce potential threat from competitors, etc. For the startups, motivation of being acquired are their innovation image in the market, leveraging value of their innovation with capabilities of large companies, getting return on the investment as quickly as possible for investors (for venture capitalists), access to different channels of marketing, becoming a serial entrepreneur, etc. (Rotstein (2016), Singh (2012), Carbone (2011)).

Enterprise spending on Artificial Intelligence and Machine Learning products and services (DataFox being one in the category) has been rising in the recent years and will exceed $\$ 57.6$ billion by 2021 (Backaitis (2018)). Oracle needs to become one of the major players to have major share of these spending. This is the one possible reason it is acquiring many Al and Machine Learning startups. These startups are using modern technologies such as Artificial Intelligence and Machine Learning (Al/ML), chatbots, big data and predictive analytics, and in turn enhancing automation. With the same objective Oracle started Startup Cloud Accelerator program in India (Press Release (2018)) and acquired DataFox.

DataFox was founded in 2013 and launched in 2014 as a contender to TC Battlefield at disrupt. It is based in San Francisco. It is developer of an Al based engine which automatically locates and pulls the most current information available on public and private businesses from sources such as news articles, blogs, etc. It provides sales intelligence to companies in B2B segment. Its platform logs more than 40 data points such as location of the offices of the companies, technological products bought by companies, 
business partners of the companies, revenue, headcounts, parent company, tech stack, growth signals, etc. (Deutscher (2018)).

DataFox is working with three groups: investment banks, growth equity firms, and venture firms, including Scale Venture Partners; sales and marketing departments of companies like Box; and strategy, research, and consulting firms like NetApp. These companies use DataFox engine to find acquisition targets (Loizos (2015)). DataFox strength in 2015 was 15 employees and its revenue was reported between US\$ 5 to 10 million. In the beginning, DataFox customers were doing $90 \%$ work manually. It is reduced to 20 to $30 \%$ with DataFox technology. Carey (2018) included DataFox acquisition in the list of notable tech acquisitions of 2018. Kim (2018) had also included DataFox acquisition among the 10 significant tech acquisitions. Manager Mint (2018) mentioned that DataFox will enrich "Oracle Cloud Applications with an extensive set of Al-derived company-level data and signals, enabling customers to reach even better decisions and business outcomes".

This paper is an attempt to analyse Oracle's acquisition of DataFox and is divided into 5 sections starting with section 1 of introduction. The next section 2 is about brief review of literature followed by research methodology in section 3. The next section 4 is about results and discussion which includes major technologies acquired by Oracle during 2018, DataFox investors \& investments made by investors in DataFox, the detail of the deal, reasons for acquiring DataFox by Oracle, sources of data of DataFox to serve its customers, DataFox customers and competitors, business model of DataFox, impact of acquisition and discussion on nine propositions. The last section 5 is about concluding remarks.

\section{Review of Literature}

This section listed literature of key features of startups happening in the present day context. Mayer and Kenney (2004) mentioned that Cisco is the best place to find future technology products of the startup ecosystem from which many big companies have emerged and continuously expand their product and services portfolios.

Xiao (2018) reported that within 4 years of acquisition, startups have low probability of survival as independent business units. He further reported that after five year of acquisition, dependence on acquirer becomes positive, although not statistically significant. He also concluded that acquired start-ups experience an extensive selection and experimentation internally by acquirers through restructuring within 4 years of acquisition and operations of acquired startup are disrupted. This is in the context of Swedish Technology Startups. 
Singh N.P.: Oracle Acquired Al Startup DataFox

Pisoni and Onetti (2018) compared the exit strategies in Europe and USA of tech startups with respect to the age of startups, their acquirer, strategies of acquirer, etc. Joseph (2017) reported that it will be great for entrepreneurs if it is end of startup era for them. He quoted how many startups in pharma industry have become billion dollar companies. He quoted Gilead Scinces, Amgen, etc.

Bonzom and Netessine (2016) identified that world biggest companies acquire or merge startups to enter new markets, for problem solving, to get rid of internal innovation stagnation, to change "risk averse and KPI driven" culture to "move fast and break things" or "done is better than perfect" culture, and having efficient technology platforms. Krikhaar and Squazzin (2018) identified four models (consolidation, transformation, tuck-in, bolt-on) of merger \& acquisition of tech and media firms in the form of their operating model framework. These models are based on degree of distinction (markets, products, geographies) and difference in size between acquirer and target company.

\section{Research Methodology}

Research methodology of the present study can be termed as exploratory cum descriptive. It is based on secondary data collected from the different sources on the Internet and websites of DataFox, Oracle and their competitors, market research companies in Al domain, etc. The content analysis of data is carried out to draw inferences about this deal and to support the following nine propositions with respect to DataFox acquisition by Oracle. Based on qualitative data, these nine propositions are evaluated on 1 to 10-point scale. "1" means proposition is not true with respect to acquisition of DataFox and "10" means absolutely true about acquisition of DataFox by Oracle.

Proposition 1: Integration of DataFox with Oracle is similar to "topup" integration model as suggested by Carbone (2011).

Proposition 2: DataFox and other startup acquisition by Oracle are part of Oracle strategies in leveraging capabilities of startups in embedding Al features into its applications.

Proposition 3: DataFox buyout is in support of the statement that startups have become an increasingly important source of research-and-development (R\&D) particularly in Al domain (Benson (2010).

Proposition 4: There is willingness on part of Oracle (established firm) to provide venture funding to entrepreneurial ventures to some extent. 
Singh N.P.: Oracle Acquired Al Startup DataFox

Proposition 5: Oracle will create entrepreneurial culture and more agile product portfolio within to meet emerging challenges with DataFox acquisition.

Proposition 6: DataFox acquisition will augment revenue streams and business lines of Oracle in near future as is the case of almost all acquisitions (Singh and Nayeem (2011)).

Proposition 7: Oracle may enhance its reputation at par with Cisco Systems and General Electric, two large multinational companies well-known for their successes in integrating acquired companies by retaining and integrating the innovative thinkers of DataFox (Kelly and Ma (2016)).

Proposition 8: Oracle will compete with other biggies in the domain of technological developments in Al, machine learning, and analytics domain.

Proposition 9: Acquirers prefer local startup for acquisition in comparison to startups of other countries.

Analysed qualitative data is used to compare similarities of the DataFox acquisition by Oracle with three frameworks of dealing of startups by biggies. These are (i) four models (Cross Leverage, New Bet, Topup, \& Double Down) of acquisition integration of Carbone (2011), (ii) four operating models (Consolidation, Transformation, Tuck-in \& Bolt-on) for charting integration strategy of Bonzom and Netessine (2016), and (iii) five corporate objectives (Innovations, Culture, New Markets, Platform, Solving Problem) of merger \& acquisition of startups by biggies as suggested by Krikhaar and Squazzin (2018).

\section{Results and Discussion}

This section presents data and its analysis with respect to various dimensions of Oracle buyout of DataFox and to support propositions. These are major technologies acquired by Oracle during 2018, DataFox investors \& investments made by investors in DataFox, the details of the deal, reasons for acquiring DataFox by Oracle, sources of data of DataFox to serve its customers, DataFox customers and competitors, business model of DataFox, impact of acquisition in terms of synergies created, product roadmap \& feature enhancement, retention of employees of DataFox, and discussion on propositions.

\subsection{Acquisition of Oracle during 2018}

Oracle acquired eight companies during 2018 as listed in Table 1. It is evident from data of acquisition given in table 1 that Oracle acquired most of the companies in analytic or artificial intelligence domain during 2018. These acquisition are done to enhance the capabilities of its existing products and 
Singh N.P.: Oracle Acquired Al Startup DataFox

services with the help of innovative technologies of acquired companies. Secondly, 2018 did not see any big ticket buyouts by Oracle in comparison to acquisition by biggies during 2018 (Table 2). DataFox with not so high valuation buyout, is identified as significant tech acquisition by industry experts. It is evident from the data given in table 1 and table 2 that Oracle acquisition of large companies had a decline during 2018.

Table 1: Acquisition of Oracle during 2018

\begin{tabular}{|l|l|l|l|l|}
\hline Date & Company & Business & Verticals & Source \\
\hline $\begin{array}{l}\text { February } \\
15\end{array}$ & Zenedge & $\begin{array}{l}\text { Intelligent Web } \\
\text { Application Security }\end{array}$ & $\begin{array}{l}\text { Servers, } \\
\text { Storage, and } \\
\text { Networking }\end{array}$ & Miller (2018) \\
\hline April 25 & Grapeshot & $\begin{array}{l}\text { Contextual Intelligence, } \\
\text { Controlling Brand }\end{array}$ & Applications & Levine (2018). \\
\hline April 30 & Vocado & $\begin{array}{l}\text { Student Information } \\
\text { Systems }\end{array}$ & Applications & Kim (2018) \\
\hline May 16 & DataScience & DataScience Platform & Middleware & $\begin{array}{l}\text { Wiggers(2018), } \\
\text { Backaitis(2018) }\end{array}$ \\
\hline $\begin{array}{l}\text { October } \\
22\end{array}$ & DataFox & Al Solution provider & Applications & Ludin (2018)) \\
\hline October & GoBalto & $\begin{array}{l}\text { Cloud solutions to } \\
\text { accelerate clinical trials }\end{array}$ & $\begin{array}{l}\text { Industry } \\
\text { Solutions }\end{array}$ & $\begin{array}{l}\text { Gagliordi } \\
(2018)\end{array}$ \\
\hline September & Iridize & $\begin{array}{l}\text { Enterprise cloud } \\
\text { platform for employee } \\
\text { training and onboarding }\end{array}$ & Applications & Stoler (2018) \\
\hline $\begin{array}{l}\text { November } \\
15\end{array}$ & $\begin{array}{l}\text { Talari } \\
\text { Network }\end{array}$ & $\begin{array}{l}\text { Sechnology } \\
\text { Teched WAN }\end{array}$ & $\begin{array}{l}\text { Industry } \\
\text { Solutions }\end{array}$ & Hill (2018) \\
\hline
\end{tabular}

Source: Author

Table 2: The Most Significant Tech Acquisitions of 2018

\begin{tabular}{|l|l|l|l|}
\hline SN & Acquirer & Acquired Company & Price paid (US\$) \\
\hline 1 & Gannett & WordStream & 150 Million \\
\hline 2 & IBM & RedHat & 34 Billion \\
\hline 3 & Oracle & DataFox & 33 Million (Valuation) \\
\hline 4 & Twilio & Sengrid & 2 Billion \\
\hline 5 & Adobe & Merketo & 4.75 Billion \\
\hline 6 & AT\&T & AlienVault & Not Given \\
\hline 7 & Cisco Systems & Duo Security & 2.35 Billion \\
\hline 8 & Siemens & Mendix & 730 Million \\
\hline 9 & DocuSign & SpringCM & 220 Million \\
\hline 10 & Salesforce & Datarama & 800 Million \\
\hline
\end{tabular}

Source: Kim (2018)

\subsection{Investors, investment, and terms of the deal}

DataFox is funded by 16 investors including 3 lead investors (Table 3). Loizos (2015) mentioned that 2.5-year-old subscription-business-model based 
DataFox which has intelligence platform raised $\$ 5$ million in funding from Goldman Sachs, an earlier investor Green Visor Capital, and from another backer, Stanford's StartX fund. According to Osborne (2018), the company had raised a total of $\$ 11.8$ million through four funding rounds. Terms of the deal with Oracle have not made public yet by both companies. But one can make guess from its investments and valuations. It had raised just under $\$ 19$ million and was last valued at $\$ 33$ million during January 2017 (Luden (2018), RealeaseSoon (2018)). Therefore, this deal could be $\$ 33$ Million plus. This deal is not in the league of the deal between Microsoft and Nokia (Singh (2014b) and Vodafone and Verizon (Singh (2014a)).

Table 3: Investors, Investment Round, and Money raised by DataFox

\begin{tabular}{|l|l|l|l|}
\hline Date & Round & Investors & $\begin{array}{l}\text { Money } \\
\text { Raised }\end{array}$ \\
\hline October 1, 2013 & Seed Round & $\begin{array}{l}\text { 13- TVSC, Starx, Green Visor Capital- } \\
\text { Simon Yoo, Sharpalo Ventures, Ram } \\
\text { Shriram, Michael Jin, Leo Polovets, } \\
\text { Keven Tawved, Jawed Karim } \\
\text { (YouTube Founder), Innospring Seed } \\
\text { fund, John Hurley, Google Ventures, } \\
\text { Gerald Risk }\end{array}$ & \$1.8 Million \\
\hline February 9, 2014 & Seed Round & $\begin{array}{l}\text { 5- Ram Shriram, John Hurley, Jim } \\
\text { Ellis, Jawed Karim, Google Ventures }\end{array}$ & Not Available \\
\hline July 22, 2015 & $\begin{array}{l}\text { Venture } \\
\text { Round }\end{array}$ & $\begin{array}{l}\text { 3-Starx, Green Visor Capital-Simon } \\
\text { Yoo, Goldman Sach }\end{array}$ & \$5 Million \\
\hline November 7, 2017 & PE Round & Undisclosed & \$5 Million \\
\hline Total & 4 & 16 & $\$ 11.8$ Million \\
\hline
\end{tabular}

Source: https://www.crunchbase.com/organization/datafox\#section-funding-rounds

DataFox did not follow legacy strategy and had support for its innovations from competitors. It is evident from the fact that CEO of Dun \& Bradstreet is on DataFox's advisory board, and executives from Factset (https://www.factset.com/), a company that provides financial information and analytic software for investment professionals has invested in the startup's $\$ 1.78$ million seed round in DataFox (Perez (2014)).

\subsection{Reasons for Oracle to Acquire DataFox}

Reason 1: Enhance Oracle capabilities of valued data it provides to customers \& Cloud based Al data Engine: DataFox has amassed a huge database of companies. Presently, covering 2.8 million public and private businesses, 5 million digital properties, 70,000 daily news articles and 756,000 unique signals in its database. DataFox will be adding 1.2 million data points each year (Luden (2018), Hari (2018), Carey (2018)). During July 2015 DataFox data base included 600,000 public and private companies 
(Loizos (2015). Oracle plans to integrate DataFox's platform with its cloud portfolio to increase the efficiency in terms of reduction in access time and cost for customers. In addition, Oracle will use resulting intelligence to enhance CRM related services (Deutscher (2018). DataFox's data engine can suck in unstructured content from different sources and then convert and pull that data in the structured form (Labbe (2018).

Reason 2: Making Al embedded in all applications: Oracle strategy is to make Al (Machine Learning) as a core feature of its all applications. Oracle requires that $\mathrm{Al}$ get embedded into virtually every solution and every application it provides to customers (Lyons (2018), Deutscher (2018)). With this objective Oracle bought DataFox to augment its Al capabilities. The two very important components on new technology setup of Oracle will be Al sales planning tool for machine learning-driven sales planning and virtual assistant for sales people. The virtual assistant has the capabilities for improving the usability of the application, and by letting users interact with the system with their voice. It should increase usage of the system in the long run (Admin (2019).

Reason 3: Leveraging Marketing Information: Oracle became a major supplier of marketing information about consumers after acquiring DataLogix Inc. in 2014. This acquisition was worth more than $\$ 1.2$ billion. Oracle plans to further leverage this data by adding value to it and making it a part of its sales intelligence operations (Deutscher (2018).

Reason 4: Bringing Sophistication in Services: Larger platform providers are acquiring Al-driven tools to extend an increasingly sophisticated level of services to their customers. Oracle has similar vision for its offering to the customers. DataFox will help Oracle in making its vision a reality and make it more competitive with its cloud application platform (Luden (2018), RealeaseSoon (2018).

Reason 5: Importance of relevant content: Relevant contents are always captivating proposition to all businesses. The contents of any customer databases will get old and out of date if not updated regularly. This necessitate the need to automate update of the existing databases with current and accurate contents/ records of businesses on regular basis. DataFox will do this job for Oracle and its customers (Luden (2018), Hari (2018).

Reason 6: Retaining the Edge of Salesforce: Oracle remains in hot competition with Salesforce for acquiring and serving its customers. Oracle plans to woo and retain all of them with the better and integrated innovations. In addition, Oracle will cross and up-sell its products (integrated or standalone) to customers who will come with DataFox (Luden (2018). 
Reason 7: Being in Al League: As per Deloitte report, it is expected that companies will spend more than $\$ 57.6$ billion on machine learning/Al technologies by 2021 in comparison to $\$ 12$ billion spending on $\mathrm{Al}$ in 2017 (Wiggers (2018). According to another source global GDP could be up to $14 \%$ larger in 2030 as a result of Al applications. This will be equivalent to an additional \$15.7 trillion to the world GDP (Hermann (2018). To compete with other biggies in Al domain Oracle needs to build capabilities which is possible via inorganic growth model. This is another reason it has acquired DataFox.

\subsection{Sources of data of DataFox to serve customers}

Perez (2014) reported that DataFox not only crawls the web to pull data but also tracks RSS feeds, and YouTube. In addition, it buys public market data and data accessed through other API partners including CrunchBase, AngelList, Linkedln, Alexa and many more. In order to create new information, DataFox analyses its existing data with algorithms. This new information could be top competitors, top customers, top regions of present business activities for large set of companies etc. The data generated and stored by DataFox is fairly of good quality, as it is updated in real-time and presented in fairly structured form. DataFox Al engine automatically flags discrepancies and remove automatically these discrepancies. DataFox provide features which helps the users in improving quality of data at their end or they can flag discrepancies to DataFox for taking in to account these discrepancies while improving quality. According to company sources, Al engines uses different sets of data, i.e., data created by algorithms, data audited by analysts, data indexed by crawlers, data anomalies tracked by scientists, data and analogies contributed by users, data purchased from partners to generate usable signals (Source: Customer of Data Foxhttps://www.datafox.com/product/company-data/). CRM Desk (2019) reported that DataFox draws heavily on publicly available sources of information about companies, including news, reference documents and company websites.

\subsection{DataFox Customers}

Data Fox customers list includes (i) Goldman Sachs, (ii) Bain \& Company, (iii) MongoDB Inc., and (iv) Twilio. These all four use data of DataFox for their sales operations (Deutscher (2018)). To mention, Goldman Sachs, which follows 70 signals, the know evolution of 20000 private business to identify targets for investment. Twilio (deck of communications) uses DataFox to qualify leads on the basis of demographic data (enrolment, location, etc.), strategic data (financing, technologies, etc.) and financial data (turnover, evolution of the capital, etc.) (Bohic (2018)). These four customers are also using DataFox platform for account management, lead generations, and to 
Singh N.P.: Oracle Acquired Al Startup DataFox

keep CRM solutions revised. DataFox offers value-added features. One of the feature is a recommendation engine that help salespeople to fine tune their search. As per DataFox salespeople can automatically identify companies similar to an organization's existing customers. Another complementary feature is an alerting tool which makes it possible to track new developments that might present deal opportunities, for example, if a firm opens a new office (Deutscher (2018)).

\subsection{DataFox Competitors}

During 2014, DataFox was focusing on professional investors, publishers, venture capital firms and others involved in private equity business. Its customers in publishing domain include VentureBeat, The Wall St. Journal, Strictly VC and The Information. This segment of customer base constitutes about 5 to 10 percent of its overall customer base. Investors and Venture Capitalists account for another 45 percent. Those using the DataFox platform include Accel Partners, Bloomberg Beta, Intuit, and Google Ventures. The Google Ventures is both a customer and an investor of DataFox (Perez (2014).

During 2014, company faced competition from Bloomberg, Thomson Reuters, Factset and Dun \& Bradstreet (Perez (2014). These firms often use off-shore analysts and manually digitize information through unintuitive interfaces. With the present features of DataFox technology, it will collect information in realtime, regardless of operating system or location. DataFox technology can also be used alongside solutions of these competitors. In addition, DataFox customers can integrate the data from sources like Bloomberg etc., and customer data stored in databases of DataFox's via its DataFox APIs (Perez (2014).

CBNinsight.com listed a list of 13 competitors of DataFox including PitchBook Data, Manta Media, etc. According to Startupranking.com, DataFox competitors are Addepar (https://addepar.com/), CB Insights (https://www.cbinsights.com), DueDil (https://www.duedil.com), Factset (www.factset.com), Mattermark (https://mattermark.com), Salesfox.io (https://www.salesfox.io), Thompson Reuter (https://www.thomsonreuters.com), Qymatrix (https://qymatix.de), Mapbox (https://www.mapbox.com), Domo (https://www.domo.com), TradeGecko (https://www.tradegecko.com), Reply.io (https://reply.io), Grow (https://www.grow.com), Gooddata (https://www.gooddata.com), Diffbot (https://www.diffbot.com), etc. Many of DataFox competitors are acquired by biggies. To mention (i) Yhat, founded in June 2013 and raised \$2.62 million in three round acquired by Altery Inc. in June 2017, (ii) Youeye, founded in January, 2011 and raised $\$ 8.464$ million in four rounds was acquired by Userzoom (https://www.userzoom.com) in March, 2016 (Dahnke (2016), and 
(iii) RockThePost, founded in 2011 acquired by OneVest (https://www.onevest.com/) in July 2014 (Weber (2014). G2world.com listed competitors and alternatives of DataFox based on four parameters/criteria as given in table 4.

Table 4: Alternatives and Competitors of DataFox

\begin{tabular}{|c|c|}
\hline Criteria for classifying competitors & Alternative and Competitors \\
\hline Best overall DataFox alternatives & $\begin{array}{l}\text { Discoverorg (https://discoverorg.com/), Zoominfo, } \\
\text { Linkedin Sales Navigator } \\
\text { (https://linkedhelper.com), Insideview } \\
\text { (https://www.insideview.com/) }\end{array}$ \\
\hline Best for SMB DataFox alternatives & $\begin{array}{l}\text { Zoominfo (https://www.zoominfo.com/), } \\
\text { Discoverorg, Nimble, Clearbit Enrichment } \\
\text { (https://clearbit.com/enrichment) }\end{array}$ \\
\hline Easiest to use DataFox alternatives & $\begin{array}{l}\text { Groove (https://www.groove.co/), Nimble, Gryphon } \\
\text { Networks, Artesian (http://www.artesian.io/) }\end{array}$ \\
\hline $\begin{array}{r}\text { Easiest to implement DataFox } \\
\text { alternatives }\end{array}$ & $\begin{array}{l}\text { Nimble (https://www.nimble.com/), Groove, LeadIQ } \\
\text { (https://leadiq.com/), Lead411 } \\
\text { (https://www.lead411.com/) }\end{array}$ \\
\hline
\end{tabular}

Source: https://www.g2crowd.com/products/datafox/competitors/alternatives

\subsection{Business Model of DataFox}

DataFox charge its customers @ $\$ 600, \$ 1,200$ and up to $\$ 2,400$ a month. It includes access for up to four users. With cheapest rate $(\$ 600)$, customers can track up to 1,000 companies; for $\$ 1,200$ rate, customers can track up to 12,000 companies. For the highest rate (up to $\$ 2,400$ ), customers can track unlimited number of companies. DataFox reported that its average client is spending around $\$ 10,000$ a year as a starting point (Loizos (2015)). Initially DataFox was also offering a three-tier pricing plan for its public beta. It was free for non-profits and journalists. It was then $\$ 49 /$ month for individuals and $\$ 399 /$ month for those at larger companies. Custom enterprise pricing model was also available (Perez (2014)). In summary, the pricing of the DataFox products depends on three parameters, i.e., size of the organization, volume of data managed, and the number of data sets purchased.

\subsection{Impact of the Acquisition}

This section presents the impact of the deal on existing applications of Oracle, synergies with other acquired start ups, new CX product, employees of DataFox, product road for DataFox.

Enriching Existing cloud based applications: As per Osborne (2018) the combination of Oracle and DataFox will enhance Oracle Cloud Applications with an extensive set of Al-derived company-level data and signals which in 
turn will help its customers to take better decisions. DataFox will sit with Oracle's existing portfolio of cloud based application business planning services like ERP, CX, HCM and SCM and enrich them with Al-driven company-level data (News (2018), Carey (2018)).

Synergies with GoBalto: Acquisition of DataFox will create synergies with recently acquired GoBalto, a cloud platform developer and software as service provider for the life science industry. GoBalto technology is used to accelerate clinical drug trials at over 90,000 research sites across $2000+$ studies in over $80+$ countries which in turn will generate additional sizable amount of data. With addition of GoBalto, Oracle will enrich its databases and GoBalto's leading industry cloud solution will significantly reduce clinical trial startup time for Oracle customers (Gagliordi (2018), Deutscher (2018)).

New CX Unity product: After acquiring DataFox, Oracle launches CX Unity product designed to provide a comprehensive view for customer engagement and interactions across channels and applications. Oracle further reported that industry has focused on a predictable customer journey but new platform CX Unity will help in aggregating and accessing data from a variety of sources throughout the cloud platform. These cloud platforms are Sales Cloud, Commerce Cloud, and others. Oracle $\mathrm{CX}^{2}$ has integrations with Oracle sales cloud, salesforce, Oracle e-business suite, OracleVoice, SAP, and Oracle human capital management cloud (https://comparisons.financesonline.com/iridize-vs-oracle-cx). Furthermore, usage of $\mathrm{Al}$ algorithm on top of it will provide deeper insights into present unpredictable buying journeys of its customers (Anderson (2018).

As it is evident from the fig 1, DataFox elevated three products of Oracle, i.e., (i) Enterprise Resource Planning (ERP), (ii) CX, and (iii) Supply Chain Management (SCM) with its Al driven capabilities. It helps in integrating and analysing $1^{\text {st }}$ party data (company data) and trusted third party data (Company level and consumer level).

Roadmap for Integration of DataFox Products under Oracle: Luden (2018) reported that Oracle is not committed to a specific product roadmap for DataFox in future. It will be keeping the product as it is for those who are already customers of DataFox (TechGig Bureau (2018). However, the architecture of DataFox integration with Oracle product portfolio suggest that Oracle may follow more or less "Top Up (Assimilate existing units into Buyer)" integration model of Carbone (2011).

\footnotetext{
${ }^{2}$ The Oracle Customer Experience Cloud (Oracle CX Cloud) is a suite of cloud-based tools for $\mathrm{CRM}$ and sales, marketing, customer service, e-commerce and other tools, such as configure, price quote tools (Source: https://searchcrm.techtarget.com/definition/Oracle-CustomerExperience-Cloud-Oracle-CX-Cloud).
} 
Employees of DataFox: Nothing is reported in the media either by Oracle or DataFox about integration of DataFox employees with Oracle. There will not be any cultural issues since both are United States companies. The difference will be entrepreneurial aspirations of DataFox employees. They wish to grow faster in the ladder. It may encourage them in finding similar environment in new startups and quitting the new arrangement. For Oracle it will not be a problem to accommodate them because of their small number.

Fig 1: Oracle + DataFox elevates decision making \& Business Performance across the enterprise

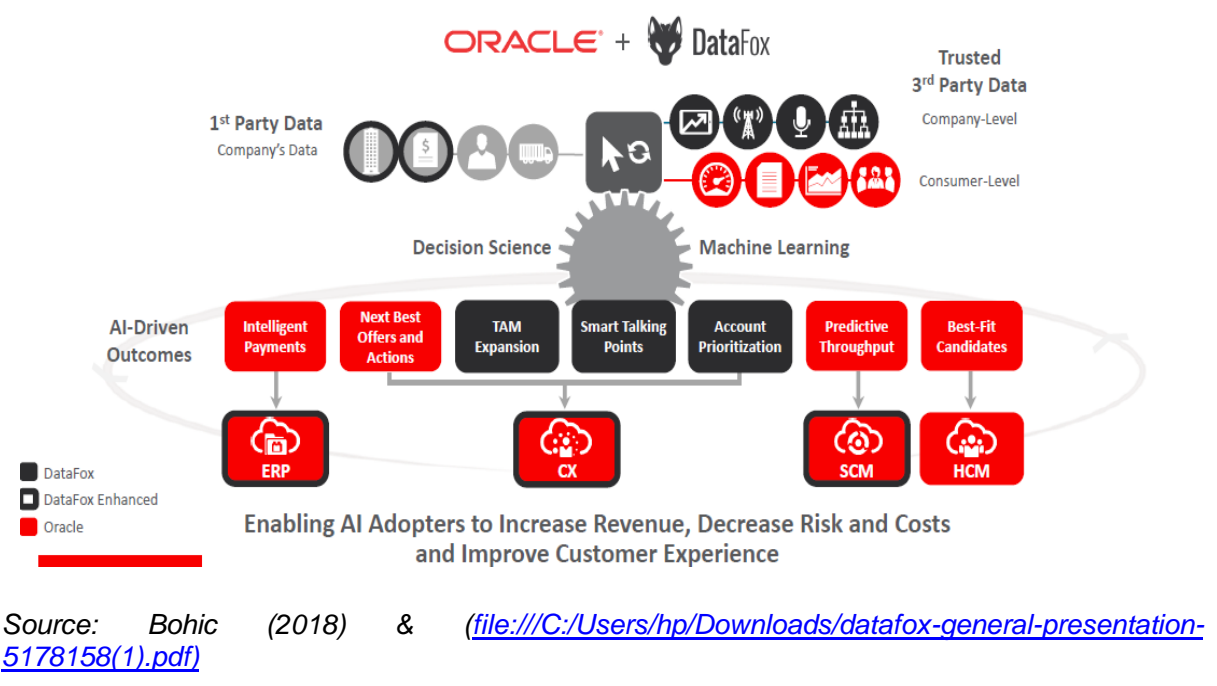

\subsection{Propositions}

Based on the analysis of data presented in the above section, nine propositions are evaluated in this section on a 1-10 point scale as given in table 5.

Proposition 1: Integration of DataFox with Oracle is similar to "topup" integration model as suggested by Carbone (2011).

According to Carborne (2011), the "Top Up" model breaks up the acquired entity into portfolio elements and consolidates it into the acquiring company. It is evident from the fig 1 that DataFox technology is embedded in ERP, CX, and SCM applications. These facts support the proposition to a great extent. 
Singh N.P.: Oracle Acquired Al Startup DataFox

Proposition 2: DataFox and other startup acquisition by Oracle are part of Oracle strategies in leveraging capabilities of startups in embedding Al features in to its applications.

It is evident from the data given in table 1 that Oracle had bought companies mainly in $\mathrm{Al}$ and Machine learning domain. Core technology of DataFox consists of usual Al-powered tools - machine-learning algorithms and natural-language processing which is a natural support of Oracle strategy (CRM Desk (2019). In addition, views of Lyons (2018), Deutscher (2018) support the proposition.

Proposition 3: DataFox buyout is in support of the statement that startups have become an increasingly important source of research-and-development (R\&D) particularly in Al domain (Benson (2010).

This is confirmed by the data presented in the above sections of this paper. The deal is all about acquiring innovation. This is also evident from the data of startup deals (Ziadi (2018)). The proposition is very true about the DataFox acquisition by Oracle.

Proposition 4: There is willingness on part of Oracle (established firm) to provide venture funding to entrepreneurial ventures to some extent.

As per McDuling (2018), Oracle does not invest in startups any more. Oracle was enthusiastic about corporate venture capital during last boom of IT. It has invested $\$ 500$ million into a start-up fund. Oracle could make money only in few cases. This is most important reason cited for a change in the strategy of Oracle in providing venture capital. This proposition is not supported by data available with respect to Oracle. However, Oracle is taking advantages of innovations of startups by acquiring them.

Proposition 5: Oracle will create entrepreneurial culture and more agile product portfolio within to meet emerging challenges with DataFox acquisition.

DataFox manpower is not mentioned in media. Oracle will utilize it in creating entrepreneurial culture and more agile product line which can meet challenges such as identifying fake news, etc. (CRM Desk (2019)). The data support this proposition to a certain extent.

Proposition 6: DataFox acquisition will augment revenue streams and business lines of Oracle in near future as is the case of almost all acquisitions (Singh and Nayeem (2011)).

DataFox buy is not as its earlier high value buyouts in $\mathrm{Bl}$ or data analytic domain (Singh and Nayeem (2011)). However, it has customers (List is given in section 4.5) which may marginally augment revenue streams for Oracle. It will enhance capabilities of applications for improving customer experience with Oracle cloud applications. 
Singh N.P.: Oracle Acquired Al Startup DataFox

Proposition 7: Oracle may enhance its reputation at par with Cisco Systems and General Electric, two large multinational companies well-known for their successes in integrating acquired companies by retaining and integrating the innovative thinkers of DataFox (Kelly and Ma (2016)).

Not much is reported about integration of innovative thinkers of DataFox but if one goes by number it should not be an issue for Oracle till it serves DataFox's customers with existing product. The data did not support this proposition.

Proposition 8: Oracle will compete with other biggies in the domain of technological developments in Al, machine learning, and analytics domain.

Companies follow two approaches to compete, i.e., organic growth model and inorganic growth model. Investments by Oracle in inorganic growth model in $\mathrm{Al}$ and machine learning domain are not comparable with IBM and other biggies as is evident from the data given in Table 2. It needs to do a bit more even to compete with its competitor Salesforce in terms of capabilities. Data did not support very strongly this proposition.

Proposition 9: Acquirer prefer local startup for acquisition in comparison to startups of other countries (Pisoni and Onetti (2018)).

This proposition is true in case of Oracle acquisition of Al startup DataFox. Oracle and DataFox belong to the United States.

Table 5: Evaluation of Propositions and linkage with existing trends

\begin{tabular}{|l|l|l|}
\hline Propositions & $\begin{array}{l}\text { Rating on 10 } \\
\text { Point Scale }\end{array}$ & $\begin{array}{l}\text { Mapping with Bonzom } \\
\text { and Netessine (2016) } \\
\text { framework }\end{array}$ \\
\hline P1:Integration of DataFox ......Carbone (2011). & 9 & Augmented Platform \\
\hline P2:DataFox and other............applications & 9 & Innovation \\
\hline P3:DataFox buyout..........Al domain & 9 & Innovation \\
\hline P4: There is willingness to ......... some extent & 1 & Not mapped \\
\hline P5:Oracle will.........DataFox acquisition & 6 & Change in Culture \\
\hline P6: DataFox acquisition ....... all acquisitions & 8 & New Markets \\
\hline P7: Oracle may enhance....... of DataFox & 6 & Culture \\
\hline P8: Oracle will compete.......analytics domain & 4 & Not Mapped \\
\hline P9: Acquirer prefer ............. other countries & 10 & Not Mapped \\
\hline
\end{tabular}

Source: Author

\section{Concluding Remark}

Acquisition of a cloud-based artificial intelligence data engine provider, DataFox, is part of the Oracle's vision for Gen2 Cloud which will offer autonomous capabilities, advanced security, improved performance and cost advantages to its customers (Cardoza (2018), Hardcastle (2018)). Oracle 
needs Al based tools to recognize fake news which are important Oracle's sources of data about companies. It is very important for Oracle to derive business value by sourcing, monitoring and integrating corporate data available in different sources. The application of machine learning algorithms and artificial intelligence tools will help Oracle in populating its CRM database with recent, quality, and accurate corporate data. This data will be in Oracle's core for developing future CRM and related technology products for customers. These new sets of quality and integrated data will help executives of the customers of Oracle zero in on the leads and opportunities with a higher success which in turn enhance their return on investment. Addition of customers like Gold man Sachs, Bain \& Company and Twilio who are utilizing DataFox's quality data to prioritize accounts, enrich leads, refresh and harmonize CRM data and identify new prospects will be of great help to Oracle in adding more customers to its fold. To conclude, the deal analysed in this research paper is true reflection of the equation (Oracle Cloud Applications+ DataFox = Even Smarter Decisions) by Levy (2018).

Comparison of the deal with Carbone (2011) models identifies a possible integration model for Oracle to integrate DataFox as Top-up. Furthermore, if one maps Bonzom and Netessine (2016) merger \& acquisitions framework of startups by biggies, Oracle will treat startups as its outsourced research and development department, it will enter new markets by acquiring startups, it will enhance capabilities of existing technological platforms, it may change risk averse and KPI driven culture by absorbing talent of startups, and it will take acquisition route of startups in solving problems of customers. As per the operating model framework of Krikhaar and Squazzin (2018), DataFox acquisition is part of a tuck-in model of charting integration strategy for Oracle.

\section{References}

Anderson, B. (2018). Oracle Aims to Address Customer Al Data Concerns with DataFox Acquisition, Launch Of CX Unity. October 23. Retrieved on December 14, from https://www.demandgenreport.com/features/news-briefs/oracle-aims-toaddress-customer-ai-data-concerns-with-datafox-acquisition-launch-of-cx-unity*.

Backaitis, V. (2018). Why did oracle buy datascience. com. Retrieved from https://digitizingpolaris.com/why-did-oracle-buy-datascience-combb415566c5b1.

Benson, D.F. (2010). Corporate Venture Capital and the Acquisition of Entrepreneurial Firms. USA: The University of Michigan. Ph. D. Thesis.

Bohic, C. (2018). DataFox: $A$ dose of $B I$ in the Oracle cloud. Retrieved from https://www.itespresso.fr/datafox-bi-cloud-oracle-199483.html.

Carbone, P. (2011). Acquisition Integration Models: How Large Companies Successfully Integrate Startups. Technology Innovation Management Review, 1(1), 26-31. doi:10.22215/timreview/490 
Singh N.P.: Oracle Acquired Al Startup DataFox

Cardoza, C. (2018). Oracle OpenWorld prepares for a next-generation cloud. Retrieved from https://sdtimes.com/cloud/oracle-openworld-prepares-for-a-nextgeneration-cloud/.

Carey, S. (2018). Most notable tech acquisition of 2018. Retreived from https://www.computerworlduk.com/galleries/it-business/most-notable-techacquisitions-of-2018-3672332/.

CRM Desk. (2018). Oracle's DataFox acquisition signals bold step in to Al. Retreived from https: //it. toolbox. com/blogs/crmdesk/oracles-datafox-acquisition-signalsbold-step-into-ai-010719..

Dahnke, P. (2018). Userzoom acquires European user research company what users do, further strengthening market leadership, Retreived from https://www.prweb.com/releases/2018/01/prweb15067919.htm

Deutscher, M. (2018). Oracle to acquire Goldman Sachs-backed sales intelligence startup DataFox. Retrieved from https: //siliconangle. com/2018/10/23/oracleacquire-goldman-sachs-backed-sales-intelligence-startup-datafox/* .

Gagliordi, N. (2018). Oracle buys GoBalto to expand health services business. Retrieved from https://www.zdnet.com/article/oracle-buys-gobalto-to-expandhealth-sciences-business/.

Hardcastle, J.L. (2018). Oracle Cloud Tech Seems Solid. But Is It Too Late. Retrieved from https: //www. sdxcentral. com/articles/editorial/oracle-cloud-tech-seemssolid-but-is-it-too-late/2018/10/.

Hari (2018). Oracle acquires DataFox, A developer of 'predictive intelligence as a service' Throughout thousands and thousands of firm data. Retreived from https://www.releasesoon.com/oracle-acquires-datafox-a-developer-of-predictiveintelligence-as-a-service-throughout-thousands-and-thousands-of-firm-data/.

Hill, R. (2018). Oracle snaffles up a chunk of sd-wan market with talari networks buyout. Retrieved from https: //www. theregister. uk/2018/11/16/oracle_acquires_talari_network/..

Joseph, F. (2017). Why the "end of the startup era could be great for enterprenuers. New York: TechCrunch. Retreived from https: //search. proquest. com/docview/1959825918/7113CC2CF6C344C8PQ/55?accountid=49732.

Kelly, C., \& Ma, C. (2016). How do established companies acquiring startups retain the innovative/disruptive/big thinkers and leverage this thinking. Retrieved from http://digitalcommons.ilr.cornell.edu/student/137.

Kim, J. (2018). Oracle adds financial aid solution Vocado to the student cloud suite. Retrieved from https: //ovum. informa. com/resources/product-content/oracleadds-financial-aid-solution-vocado-to-the-student-cloud-suite.

Kim, L. (2018). The most significant tech acquisitions of 2018. Retreived from https://www.inc.com/larry-kim/the-most-significant-tech-acquisitions-of2018.html.

Labbe, M. (2018). Oracle-DataFox acquisition could expand user's Al Options. Retrieved from https: //searchenterpriseai. techtarget. com/news/252454033/Oracle-DataFox-acquisition-could-expand-users-Aloptions.

Levine, b. (2018). Oracle data cloud combine grapeshot and moat acquisitions for a pre bid as filter. Retrieved from https: //martechtoday. com/oracle-data-cloudcombines-grapeshot-and-moat-acquisitions-for-a-pre-bid-ad-filter-227461.

Levy, M.R. (2018). Oracle acquires DataFox. Retrieved from https: //gzconsulting. org/2018/11/09/oracle-acquires-datafox/. 
Singh N.P.: Oracle Acquired Al Startup DataFox

Loizos, C. (2015). DataFox Hunts Down \$5 Million in Fresh Funding. Retrieved from https://techcrunch.com/2015/07/22/datafox-hunts-down-5-million-in-freshfunding $/{ }^{*}$.

Luden, I. (2018). Oracle acquires DataFox, a developer of 'Predictive intelligence as a service' across millions of company records. Retrieved from https://techcrunch.com/2018/10/22/oracle-acquires-datafox-a-developer-ofpredictive-intelligence-as-a-service-and-a-trove-of-company-information/* .

Lyons, J. (2018). Oracle Buys DataFox, Pledges to Embed Al into everything. Retrieved from https://www.sdxcentral.com/articles/news/oracle-buys-datafoxpledges-to-embed-ai-into-everything/2018/10/ *

Manager Mint. (2018). TechCrunch: Oracle acquires DataFox, a developer of 'predictive intelligence as a service' across millions of company records. Retrieved from https://managermint.com/techcrunch-oracle-acquires-datafox-adeveloper-of-predictive-intelligence-as-a-service-across-millions-of-companyrecords/.

Mayer, D., \& Kenney, M. (2004). Economic Action Does Not Take Place in a Vacuum: Understanding Cisco's Acquisition and Development Strategy. Industry and Innovation, 11(4), 299-325. doi:10.1080/1366271042000289333

Mcduling, J. (2017). Why Oracle does not invest in startups anymore. Retreived from https://www.afr.com/technology/why-oracle-doesnt-invest-in-startups-anymore20170504-gvypmf.

Miller, R. (2018). Oracle grabs Zenedge as it continues to beef up its cloud security play. Retrieved from https: //techcrunch. com/2018/02/16/oracle-grabs-zenedgeas-it-continues-to-beef-up-its-cloud-security-play/..

NewsHub. (2018). News, Al and ML latest: Oracle acquires Al company-intelligence firm DataFox. Retrieved from http://nhub.news/2018/10/ai-and-ml-latest-oracleacquires-ai-company-intelligence-firm-datafox/.

Osborne, C. (2018). Oracle acquires DataFox, brings Al-based company data management to cloud apps. Retrieved from https: //www. zdnet. com/article/oracle-acquires-datafox-brings-ai-based-company-datamanagement-to-oracle-cloud/.

Perez, S. (2014). DataFox Offers Predictive Intelligence-As-A-Service, Enabling Better Investment Decisions. Retrieved from https: //techcrunch. com/2014/09/09/datafox-offers-predictive-intelligence-as-a-service-enablingbetter-investment-decisions/..

Pisoni, A., \& Onetti, A. (2018). When startups exit: comparing strategies in Europe and the USA. Journal of Business Strategy, 39(3), 26-33. doi:10.1108/jbs-02-20170022

Press Release (2018). Oracle on-boards new startups to enable cloud innovation in india. Retrieved from https://www.oracle.com/in/corporate/pressrelease/oraclestartup-cloud-accelerator-4th-batch-2018-08-13.html.

Rotstein, D. (2016). Why do big companies buy start-ups?, What are the motivation behind exits. Retrieved from https: //cofounderslab. com/discuss/why-do-bigcompanies-buy-startups-what-are-the-motivators-behind-exits.

Singh, N.P. (2014a). Verizon acquired Vodafone: Analysis of market reaction. Industrija, 42(3), 163-182. doi:10.5937/industrija42-5782

Singh, N.P. (2014b). Microsoft Acquired Nokia in Unipolar Operating System Market. Independent Journal of Management and Production, 5(3), doi:10.14807/ijmp.v5i3.166 
Singh N.P.: Oracle Acquired Al Startup DataFox

Singh, N.P., \& Nayeem, M.M.J. (2011). Critical Analysis of Expansion Strategies of SAP, IBM, Oracle and Microsoft in the area of Business Intelligence. International Journal of Strategic Information Technology and Applications, 2(2), 23-43. doi:10.4018/jsita.2011040103

Stoler, T. (2018). Oracle acquires Tel Aviv based user training start up Iridize. Retrieved from https://www.calcalistech.com/ctech/articles/0,7340, L3746447,00.html.

TechGig Bureau. (2018). Oracle acquires predictive intelligence startup DataFox. Retreived from https://content.techgig.com/oracle-acquires-predictiveintelligence-startup-datafox/articleshow/66363447.cms.

Weber, H. (2014). Startup investment site rockthepost merges with the cofounder matchmakers at cofounderslab. Retrieved from https://venturebeat.com/2014/07/16/startup-crowd-investing-site-rockthepostmerges-with-the-cofounder-matchmakers-at-cofounderslab/.

Wiggers, K. (2018). Oracle acquires machine learning platform datascience.com. Retrieved from https: //venturebeat. com/2018/05/16/oracle-acquires-machinelearning-platform-datascience-com/.

Xiao, J. (2018). Post-acquisition dynamics of technology start-ups: drawing the temporal boundaries of post-acquisition restructuring process. In IDEAS Working Paper Series from RePEc. St. Louis. 